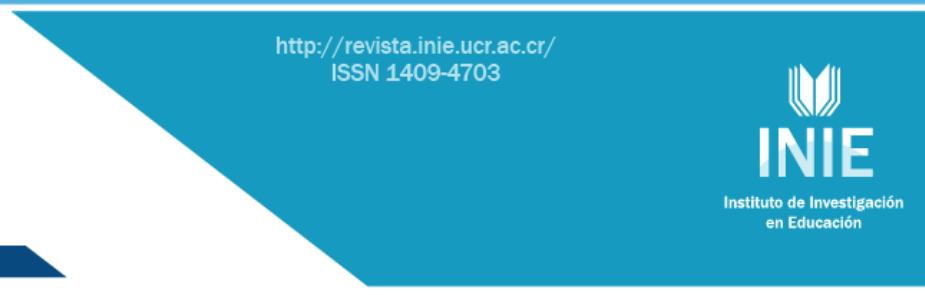

\title{
IMPLEMENTATION PROCESS OF TECHNOLOGY IN EDUCATION: THE CASE OF BLACKBOARD 9.1 IN THE UNIVERSITY OF MANCHESTER
}

PROCESOS DE IMPLEMENTACIÓN DE TECNOLOGÍAS EN EDUCACIÓN: EL CASO DE BLACKBOARD 9.1 EN LA UNIVERSIDAD DE MANCHESTER

\section{Volumen 13, Número 3}

Setiembre - Diciembre

pp. 1-31

Este número se publicó el 30 de setiembre de 2013

Rebeca Mora Rodríguez

Revista indizada en REDALYC, $\underline{\text { SCIELO }}$

Revista distribuida en las bases de datos:

CATÁLOGO DE LATINDEX, IRESIE, CLASE, DIALNET, DOAJ, E-REVIST@S, SHERPA/ROMEO, QUALIS, MIAR

Revista registrada en los directorios:

ULRICH'S, REDIE, RINACE, OEI, MAESTROTECA, PREAL, CLASCO 


\title{
IMPLEMENTATION PROCESS OF TECHNOLOGY IN EDUCATION: THE CASE OF BLACKBOARD 9.1 IN THE UNIVERSITY OF MANCHESTER
}

\author{
PROCESOS DE IMPLEMENTACIÓN DE TECNOLOGÍAS EN EDUCACIÓN: EL CASO DE \\ BLACKBOARD 9.1 EN LA UNIVERSIDAD DE MANCHESTER
}

Rebeca Mora Rodríguez ${ }^{1}$

\begin{abstract}
Information and communication technologies are changing the teaching and learning process around the world. Virtual learning environments are one of the most common technologies that universities are adopting nowadays. According to the literature, the implementation of any technology into an organization will affect the different groups within it. Thus, there are many theories about how the implementation process must be done in order to adapt the community to the new system. This article aims to present the results of a research that studied how the implementation process of Blackboard 9.1 in the University of Manchester was undertaken by lecturers and technologists of this institution. Two different questionnaires were applied to both groups. Following a qualitative approach for the open questions and a quantitative approach for the closed questions, all the responses from the participants were analysed. It was concluded that the implementation process of Blackboard 9.1 was management-driven instead of teaching-driven. Therefore, political and economical forces were involved in it. Additionally, the research revealed that neither students nor teachers or technologists were consulted before the execution process of Blackboard 9.1 started. Since the research was developed as a case study, the results cannot be generalised. Nevertheless, the study can be used to illustrate a more general idea about technology implementation in education.
\end{abstract}

Key words: IMPLEMENTATION, ADOPTION, ADAPTION, VIRTUAL LEARNING ENVIRONMENT, UNIVERSITY OF MANCHESTER, ENGLAND.

Resumen: Las tecnologías de la información y comunicación están cambiando los procesos de enseñanza y aprendizaje alrededor del mundo. Los Entornos Virtuales de Aprendizaje son una de las tecnologías más comunes que las universidades están adoptando en la actualidad. De acuerdo con la literatura, la implementación de cualquier tecnología en una organización afecta a los diferentes grupos que pertenecen a ella. De esta manera existen muchas teorías sobre cómo el proceso de implementación debe ser realizado con el fin de que la comunidad se adapte al nuevo sistema. Este artículo tiene la finalidad de presentar los resultados de una investigación que estudió la manera en se llevó a cabo el proceso de implementación de Blackboard 9.1 entre profesores y tecnólogos en la Universidad de Manchester. Dos cuestionarios fueron aplicados a ambos grupos. Las respuestas fueron analizadas siguiendo un enfoque cualitativo para las preguntas abiertas y un enfoque cuantitativo para las preguntas estructuradas. Se concluyó que el proceso de ejecución de Blackboard 9.1 fue manejado desde una perspectiva administrativa en vez de educativa, involucrando fuerzas políticas y económicas de la institución dentro del proceso. Adicionalmente, la investigación reveló que ni estudiantes, ni profesores, ni tecnólogos fueron consultados antes de que el proceso de ejecución de Blackboard 9.1 comenzara. Debido a que la investigación fue desarrollada como un estudio de caso, no puede ser generalizada. Sin embargo, el estudio puede servir para ilustrar una idea general sobre implementación de tecnología en educación.

Palabras clave: IMPLEMENTACIÓN, ADOPCIÓN, ADAPTACIÓN, ENTORNO VIRTUAL DE APRENDIZAJE, TIC, UNIVERSIDAD DE MANCHESTER, INGLATERRA.

\footnotetext{
${ }^{1}$ Docente de Inglés, Colegio Victoria. Bachiller en Educación Preescolar, Universidad de Costa Rica, Máster en Tecnologías Digitales, Comunicación y Educación, Universidad de Manchester, Reino Unido.
}

Dirección electrónica: rebe1982@gmail.com

Artículo recibido: 20 de marzo, 2013

Aprobado: 12 de setiembre, 2013 


\section{Introduction}

The development of technology around the world is influencing many aspects of daily life. As stated by Yuen, Law and Wong (2003, p. 158) 'during the past decade there has been an exponential growth in the use of information and communication technology (ICT) which has made pervasive impacts both on society and on our daily lives.' This technological impact is also affecting the education sector where the introduction of technologies has been increasing in the last decades following different approaches of technology implementation. According to Cradler (1999, párr. 1) 'careful planning is a prerequisite for the effective implementation of technology and telecommunications in education and training'. Therefore, the implementation process of technology must be based on the specific needs that the institution is trying to meet with its use.

The proliferation of information technologies is also increasing in higher education and the virtual learning environments is one of the most common technologies that it is being used at this level. A considerable amount of literature has been published on virtual learning environments; since these are complex systems which can be perceived in different ways. On the one hand, some authors indicate that virtual learning environments are web based systems oriented to facilitate the learning process of the students through the student-student and student-teacher interactions. On the other hand, these systems are defined as a studentcentred system where the student is not only active but also actor of its own learning process.

Nowadays, many higher education institutions are implementing these tools in order to promote e-learning teaching and improve education through the use of technologies. Nonetheless, as any complex technological intervention, the implementation of this technology requires specific planning that involves different groups, as mentioned by Dutton, Cheong and Park (2004, p. 70) 'other relevant social groups include the specialist developers who implement systems within organizations; students as users; and administrators and senior managers, who often regulate and sometimes mandate the use of technology'.

The process of technology implementation has different stages depending on the approach that is followed. This research studied the implementation process of Blackboard 9.1 in the University of Manchester. It focused mainly on the stages of adoption and adaption of the implementation from the lecturers' perspective who participate on the pilot projects, and the technologists in charge of the whole process. The aims of this research were to find out 
how the implementation process of Blackboard 9.1 was undertaken in the University of Manchester. Therefore, the two research questions were:

1. How the implementation process of Blackboard 9.1 in the University of Manchester was undertaken by the technologists?

2. How the implementation of a new technology as Blackboard 9.1 is undertaken by the lecturers of the University of Manchester in the phases of adoption and adaption?

\section{Literature review}

\subsection{Information and Communication Technologies in Education}

The development of information technologies has an important impact in education since the early 1980's. 'In the UK during the 1980s major government projects supported work in universities and other centers to collaborate with teachers in the design and development of software specifically for schools, and to provide teacher professional development in the curriculum integration and use of these materials.' (McDougall and Jone, 2006, p. 355). According to Moersch (1995, p. 40) "In school systems nationwide, technology has been the focus of curriculum renewal projects and school funding debates". The constant use of information technologies is present in many aspects of daily life. As Tearle (2003, p.567) suggests 'ICT has impacted on all aspects of society over recent years, and its potential to transform education continues to be widely acclaimed'. Hence, education institutions have been implementing technology for some decades in order to improve the teaching and learning process.

According to Cooper and Zmud (1990, p. 123) 'Information technology is viewed in abroad sense as it refers to any artifact whose underlying technological base is comprised of computer or communication hardware and software'. In terms of education, the approach to introduce ICT in the learning process has been changing over the years. In the early eighties the attempt to introduce technology into education was related to the introduction of computers to teach computer literacy to the students (Moersch, 1995, p. 40). However, in the last decades 'ICT has been increasingly embedded within a broader framework of education reforms that aimed to develop students' capacities for self-learning, problem solving, information seeking and analysis, and critical thinking, as well as the ability to communicate, collaborate and learn' (Yuen et al. 2003, p. 158). 


\subsection{Implementation of ICT in education}

The implementation of ICT in a new environment is a complex process that involves participation of many parts. According to Cooper and Zmud (1990, p. 124) 'IT implementation is defined as an organizational effort directed toward diffusing appropriate information technology within a user community'. As Benson and Whitworth (2007, p. 76) suggest 'various stakeholders are included in these negotiations: learners; teachers; planners; institutional leadership; and the affected public'. The implementation of a new element will always embrace change and some of the parts involved in the implementation can resist adapting to changes. Hall, Loucks, Rutherfor and Newlove (1975, p. 52) indicate that 'change leads to consternation for some, indignation for others, shock for still others, and hope for a few'. Therefore, the adoption of a new technology needs to follow a process in order to achieve the goals of the implementation. In addition, Hall et al. (1975, p. 52) suggest that change or innovation adoption is not accomplished in fact just because a decision maker has announced it. Instead, the various members of a user system, such as teachers and professors, demonstrate a wide variation in the type and degree of their use of an innovation.

Generally, the fear to change usually occurs at the beginning of the process, as Fullam (1993, p. 25) indicates, 'under conditions of uncertainty, learning, anxiety, difficulties, and fear of the unknown are intrinsic to all change processes, especially at the early stages'.

According to Yuen et al (2003, p. 159) 'the study of technology implementation in organizations started around the 1950's'. Nonetheless, the approach to put into operation technology in education was developed years later based on different approaches of technology implementation of companies and organizations. As reported by Wisema cited by Yuen et al (2003, p. 159) the implementation of information technology started based on three main objectives for information system use. First, 'to improve business efficiency by automating information processing'. Second, 'to improve management effectiveness by satisfying information needs'. Finally, 'to improve competitiveness by affecting the business strategy'. Since then, many authors have proposed different approaches concerning the implementation of technology into education.

Some authors suggest implementation from a level of non-use until a level of infusion where the technology is perceived as a process, product and tool and it is used to its full potential (Hall et al, 1975, Cooper \& Zmud, 1990, Moersch, 1995). On the other hand, based on a framework created for information management systems in organizations, Yuen et al 
(2003, p. 160) indicate that 'Telem (1996) presented a framework for school management information system implementation, which included five components, namely, technical, structural, psychosocial, goals and values, and managerial'. This framework revealed that 'the change involved in ICT implementation in schools is a complex process and needs special attention even when the change involved is related to management and does not involve teaching and learning in schools' (Yuen et al, 2003, p. 160). Fullam provides an extended approach regarding how education institutions must face the change and he suggests that the formulation of a common vision is one of the most difficult steps in the implementation process. In addition he concludes, 'the goal then is to get into the habit of experiencing and thinking about educational change processes as an overlapping series of dynamically complex phenomena' (1993, p. 21).

Many researchers have developed different models to understand IT implementation. Kwon and Zmud (1987) suggest that a variety of individual, organizational and technological forces are important to IT implementation effectiveness. They put forward a six phase implementation model for information systems based on the change model proposed by Lewin (1952); consisting on the phases of initiation, adoption, adaption, acceptance and infusion. In the 'initiation' stage the process consists in scan all the organizational problems and matches the IT solution for them. In the 'adoption' phase the process is based on rational and political negotiations to get organizational backing for implementation of the IT application. The purpose on this stage is to reach a decision and to invest resources to accommodate the implementation effort. In the 'adaption' phase the IT application is developed, installed and maintained. All of the organizational procedures are revised and developed. During this stage, organizational members are trained and finally, the IT is available for use in the organization. The stage of 'acceptance' is the process whereby members of the organization are induced to commit with the new IT application usage. Here, eventually it is expected that the application is employed in an organizational work. In the 'routinization' stage the use of the IT application is encouraged as a normal activity. The organization's governance systems are adjusted to account for the IT application; and the IT application is no longer seen as something new. Finally, during the 'infusion' phase, increased organizational effectiveness is obtained by using the IT application in an integrated manner. The final result is to use the IT application within the organization to its full potential. (Kwon and Zmud, 1987) 
Moreover, Cooper and Zmud (1990) indicate that there are several important factors in order to reach an effective implementation. Some of these factors are, top management support of the implementation effort, good IT design, and appropriate user-designer interaction and understanding'. In addition the authors mention that 'the implementation success occurs when commitment to change and the implementation effort exists, and management of the process is guided by the organizational change theories'. Finally, they add that the interests of IT stakeholders affect implementation efforts. Therefore, the success of the implementation will 'depend upon recognizing and managing this diversity' (Cooper and Zmud, 1990, p. 124).

Furthermore, Keller (2005, p. 300) proposes that 'in the context of information systems implementation research and organization theory, implementations is viewed as stages within a process describing new technologies as organizational innovations'. The author describes that one of the most common approach is the one that explains the process into three different stages: initiation, development and implementation/termination.

\subsection{Implementation of Virtual Learning Environments (VLEs)}

Over time the use of VLEs has become more widespread in the educational system. These systems are defined as

web-based software products, offering sets of Internet tools which allow the management of teaching materials, synchronous and asynchronous communication and e-mail services. A VLE allows interactions and knowledge sharing with other participants and instructors' and providing access to a wide range of resources. (Heaton-Shrestha et al, 2005, p. 371, Wilson 1996 cited by Chou and Liu, 2005, p. 65)

According to Finkelstein (2006, p. 4) the virtual learning environment 'offers a vast array of permutations for interacting and sharing knowledge with students. E-mail, discussion threads, web resources, blogs, online reading materials, and recorded audio or video are just a few of the more common means to reach learners online'.

Virtual learning environments help to support distance and face-to-face education. Jonassen, Davidson, Collins, Cambell and Hagg (1995, p. 15) suggest that 'virtual learning environments and tools can replace the deterministic, teacher-controlled model of distance instruction with contextualized work environments, thinking tools, and conversation media that 
support the knowledge construction process in different settings'. Moreover, Chin (2003, p. 7) mentions that 'they can maintain good communications links and there are opportunities for automated assessment. In terms of widening participation VLEs can provide support and resources to say, part time students who can't always travel to the campus'. However, Fry, Ketteridge and Marshall (2003, pp. 148-161) argue that 'these learning environments cannot entirely substitute for conventional methods as there are numerous factors that affect their execution such as psychological, sociological, human computer interaction and cultural impacts'.

There are different types of VLEs available on the market that can be suitable to the different needs that an education institution has. The differences of the system are based on the way that it is developed. According to Benson and Whitworth (2007, p. 81) each type of VLE reflects different divisions of labour. These authors identified four types of VLEs; the commercial systems, the open source systems, the home grown systems and the 'Ad hoc' systems. On the commercial systems 'companies who own these systems license them to institutions and offer upgrades and technical support under contract. While institutions are typically allowed to customize the systems to some degree, changing the source code is usually reserved for the system owners'. One example of these systems is Blackboard 9.1. On the open source systems, e.g., Moodle, the 'owners of these systems provide the source code to institutions for free, software upgrades are free but institutions must provide their own technical support staff to change configurations, modify source code, and troubleshoot problems'. The home-grown systems are locally developed, as Benson and Whitworth suggest 'these systems may serve an entire institution, or single programs. Home-grown systems are maintained by technical staff local to the program/institution and the program/institution controls all changes'. Finally, the 'Ad hoc' systems are 'those evolving from a single instructor's actions in moving a course or courses online. "Ad hoc" systems are typically less complex than other types: the distinctive element here is a disappearance of the boundaries between developer and instructor' (Benson and Whitworth, 2007, p. 82).

In terms of higher education, there has been a growing impact related to the implementation of technology as virtual learning environments. On the one hand, Roberts, Grout and Worden (2007, pp. 4-5) argue that 'there is an increasing popularity of adopting these virtual environments in business and academic institutions, however, in some cases these avenues are adopted with the notion of simply following the actions of fellow institutes 
and corporations without carefully considering their application. As a result of this; these new environments offer nothing in value over conventional approaches and in fact provide additional problems'. On the other hand, according to Barajas and Gannaway (2007, p. 112) 'European universities have taken steps to integrate e-learning, and it can be argued that there are some traditional European universities that have had sufficient experience implementing e-learning to serve as models for other universities who are ready to improve elearning capability.' Under this argument Barajas and Gannaway (2007, p. 113) suggest a model of technology implementation based on a peer-review approach:

The first step in a peer-review is to learn as much as possible about the university vis-ávis e-learning through documentation and questionnaires made available before a peer review team visits the university to interview administrator, faculty, librarians, students, course designers, Information technology (IT) staff, and others involved in e-learning. Finally the review team analyses their data and reports findings and recommendations to the university.

Likewise, Keller (2005) proposes three different models of VLE's implementation based on models from information system implementation research and organization theory. The first model is implementation as technology acceptance. In this model 'the user must experience perceived usefulness and perceived ease of use. The VLE must enhance the resolving of the educational tasks, both on behalf of the students and the teachers' (Keller, 2005, p. 308). The second model is implementation as diffusion of innovations. Here the model 'regards the VLE as an innovation to be diffused in an organization' (Keller, 2005, p.308). The third and final model is the implementation as a learning process; a process seen from communities of practice approach theory. Thus, the VLE implemented must facilitate participation rather than being easy to use. 'This approach is based around the principles of engagement, intelligibility and participation. It assumes that learning is a social process and that an academic discipline represents a community, to which a student is enculturated' (Weller, 2007, p. 19). In addition, Keller (2005, p. 307) mentions, 'the design of the VLE should provide interactivity and consider the membership of different communities of practice'.

Finally, another approach for the implementation of technology that helps to understand some of the findings of this research is the social shaping technology approach or SST. The 
SST approach focuses on how people design, deploy and appropriate different types of technologies in actual social settings (Dutton et al, 2004, p. 70). Furthermore, 'social shaping approaches encourage a concentration on the social and political processes through which terms such as failure, disaster, benefits, or successes come to be ascribed to technological systems' (Wilson and Howcrof, 2000, p. 94). This approach considers 'a wide range of perspectives and concepts that attempt to explain the relationship between technology and society' (Mingers and Willcocks, 2004, p. 331). Likewise, the social shaping of technology tries to explain the social process of the conception, invention, design and development of technology, seeing this as embodying particular social relationships (Mackay and Gillespie, 1992, p. 686). The main idea of the social shaping of technology approach is to see the technology as part of the social environment and not as an individual artifact. Technology is not viewed as an independent variable; no objective account of it SST is seen as providing ways of conceptualizing how information technology is integrated into the analysis of human societies' (Aidemar, 2007, p. 444).

\subsection{Stakeholders' consultation on VLEs implementation process}

\subsubsection{Stakeholders' interests}

The term 'stakeholders' is defined as those who have a stake in an organization. This represents a radical shift, from those who affect the organization, to those who are affected by it' (Stenberg, 1997, p. 3). During the implementation process of any technology the consultation with the groups that are affected by it, is significant and VLE implementation is not an exception. Weller (2007, p. 49) indicates 'when dealing with a complex system such as a VLE, which has users from multiple perspectives and thus has to satisfy a variety of objectives, some consultation with these different user groups is essential'. According to Whitworth (2005, p. 686) 'as technological products, virtual learning environments (VLEs) are shaped in many ways: overtly (by their designers); subtly (for example, by resource restraints and other environmental factors); and subsequent to their 'delivery', by user adaptations and subversions of the designers' intent'. Therefore, many parts are affected by the implementation of a new VLE and many people have different interests about it. In addition, Whitworth (2005, p. 686) indicates 'each stakeholder group brings to the development process a certain culture, filled with assumptions, values, prior experiences, calculations of costs and benefits, and the like'. 
Regardless the technology that is going to be implemented; the stakeholders will have different interests about how the new technology will influence them. Thus, the consultation with these groups is vital to reach a successful implementation. Weller (2007, p. 50) suggests that 'as well as improving the potential quality of the decision, the other benefit in conducting a stakeholder consultation exercise is that in begins to engage a range of users with the broader context within which the VLE will operate'. That is how throughout the implementation process people are acculturate to the new technology and a process of acceptance is developed along with the implementation. Weller indicates that the variety of stakeholders that need to be consulted will vary depending on each institution but in terms of higher education they will probably include: students, academic staff, technical staff, administrative staff, support staff and senior management. (Weller, 2007, p. 51). Each of these groups will have different expectations about the VLE implementation. For instance, Weller (2007) suggests that the students may be interested in different needs based on study forms. The academic staff may regard specific needs of subject areas, teaching and researching. The technical staff will have the task of implementing the VLE in a technical sense. The administrative staff will concern about the administrative system of the VLE. The support staff will have specific interests about the technical support that they have to provide. Finally, the senior managements

are likely to have very specific expectations of a VLE. Depending on how they view elearning in general they may see it anywhere from a necessary evil, which might be summarised as 'everyone else has to get one so we have to have one', to a crucial component in meeting the strategic directives of the institution. (Weller, 2007, p. 51)

According to Cervero and Wilson cited by Benson (2002, p. 448) there are three different types of stakeholders' interests;

expressed interests, which are the stated, or revealed, preferences of individuals involved in the planning process; ideal interests, which refer to "what is really in the interest or good of a person, whether she or he thinks so or not'; and real interests, which are the 'norms, values, and purposes implicit in what planners do.

On the other hand, Benson (2002, p. 49) proposes a second classification of interests: overarching interests and operating interests. She suggests that 'an operating interest is a perspective of an overarching interest held by one or more stakeholder groups'. This means 
that even though one interest is shared by different stakeholder groups (overarching interest) each group will have their own viewpoint (operating interest) about the general interest; thus, some conflicts can be generated based on the operating interest that every stakeholder group has.

\subsubsection{Stakeholders Influence}

As any organization a university has different social systems. Whitworth (2005, p. 685) describes universities as 'social systems existing within various environments: natural, cultural, commercial, political, technological, and more'. In addition, he mentions that 'an innovation or change in any of these environments will impact upon the organization'. The introduction of technology into an organization as a university will have special impact in some of the university systems, as Whitworth (2005, p. 685) argues 'e-learning is becoming an increasingly integrated part of both the cultural and technological environment of the modern university, and constitutes a change in these environments. Its introduction should therefore be recognised as a process with political implications'.

The different interests that the stakeholder groups have are also motivated for the position and the level of power that these groups have within the different systems of the university. According to Cervero and Wilson cited by Benson (2002, p. 449) 'the ability of a stakeholder to influence the negotiations, and thus the resulting program, is determined by the power relationship among the stakeholders'. Therefore, some stakeholders will have more power and they will be able to shape the implementation process of the new technology based on their own 'operating interests'. 'This stakeholder capacity to act may be 'socially systematic', derived from the organizational and political structures within which they act, derived from their role or position with respect to the planning task at hand' (Cervero and Wilson cited by Benson, 2002, p. 449).

The different perspectives and the level of power that the stakeholder groups have, can lead to a conflict based on the decisions taken throughout the technology implementation process. However, regardless there is a conflict or not 'It is how an organization deals with this potential conflict that allows an assessment of its democratic credentials. Conflict may be allowed to be expressed, and then resolved as consensually as possible: Or it may be repressed, with objectors denied any voice in the innovation process' (Whitworth, 2005, p.686). About this point Benson (2002, p. 449) suggests that 
if conflicting operating interests are identified early, they can be addressed reasonably without causing any unnecessary stress on the process and the stakeholders. Uncovering conflicting operating interests late in the planning and implementation process can undermine the effectiveness of the process and the stakeholders.

\subsection{Blackboard: the VLE of the University of Manchester}

The University of Manchester is one of the main universities of the United Kingdom and it was created from the coming together of the Victoria University of Manchester and UMIST in October 2004. One of the goals of this university is to become one of the best universities in the world. As it is mentioned by Morgan (2010, p.3) 'The University of Manchester aims to be one of the top 25 universities in the world and is committed to achieving this by $2015^{\prime}$. Therefore, in order to develop an effective e-learning platform and to improve the teaching and learning process offered; the university decided to sign a contract with Blackboard Consulting Services to build an e-learning platform to the whole institution. 'The Blackboard Consulting Services engagement with the University of Manchester had two key strands: Project Planning and Project Implementation, which characterize a successful deployment of an enterprise e- Learning and managed hosting environment' (Morgan, 2010, p.3).

\subsubsection{Blackboard Vista and Blackboard 9.1}

In July 2007 the University of Manchester signed a contract to operate Blackboard Vista as the main virtual learning environment of the institution. As it was stated on the senate of June 2007 the University had reaffirmed its commitment to implement Blackboard Vista as its Virtual Learning Environment (VLE) and, furthermore, to ensure that it was operational from the start of the new academic year by using Blackboard's hosting service on a short term basis, albeit that this arrangement might be extended further in due course' (p. 162).

Since the complete implementation of Blackboard Vista in 2008 until 2010 the number of people using this platform in the university rapidly grew. According to the senate of the University of Manchester in June 2010 'The usage of e-Learning technologies had expanded significantly since the launch of the Blackboard project in June 2007 so that the number of Blackboard Vista active users had increased from approximately 3,000 in June 2008 to 30,000 in June 2010' (2010, p.339). Therefore, the university decided to move forward with the update of Blackboard Vista to Blackboard 9.1 because as it was mentioned in the same 
senate it was hoped that greater use of Blackboard Vista would be facilitated by the upgrade to version 9.1 which was more user-friendly than the current version' (2010, p.339).

\section{Methodology}

\subsection{Case Study}

The implementation of technology in any institution requires a high organization and it is a unique experience in all the cases. As Guri-Rosemblit quoted by Guri-Rosemblit (2005, p.178) suggests 'the academic goals, potential clienteles and organizational infrastructure of each are diverse, and these profound differences shape the ways in which the new technologies are mobilized in each context to achieve different end products'. Each case of technology implementation is different because every institution has different features and needs; Downs and Mohr (1976) argue that the adoption of an innovation will vary among different organizations based on the typology and the characteristics of the innovation and the way that it is contemplated by the organization. Therefore, the implementation process of Blackboard 9.1 in the University of Manchester was researched as a case study.

According to Cohen, Manion and Morrison (2010, p. 253) 'the case studies are set in temporal, geographical, organizational, institutional and other contexts that enable boundaries to be drawn around the case'. In addition, Denscombe $(2007$, p. 35$)$ indicates that case studies 'focus on one (or just a few) instances of a particular phenomenon with a view to providing an in-depth account of events, relationships, experiences or processes occurring in that particular instance'. This particular case study focuses on the implementation process of Blackboard 9.1 from an organizational point of view based on the experiences of the lecturers who participated in the pilot projects of Blackboard 9.1 and it is also based on the perspective of the e-learning team in the Faculty of Humanities. Since any implementation requires an extensive process with different stages, this research is focused on two stages; that can are called 'adoption' and 'adaption' stage according to the model proposed by Kwon and Zmud (1987).

\subsubsection{The Research Questions}

As it was mentioned above, the implementation of a new technology in an educational institution is different in every single case because every institution has its own 
characteristics. The University of Manchester is not an exception. Thus, as a student who participated in the pilot projects of Blackboard 9.1 implementation, it was interesting to find out the different stages that this process had had from an organizational point of view. In order to understand the whole process from the perspective of the technologists and lecturers involved, the following research questions were developed.

1. How the implementation process of Blackboard 9.1 in the University of Manchester was undertaken by the technologist?

2. How the implementation of a new technology as Blackboard 9.1 was undertaken by the lecturers of the University of Manchester during the phases of adoption and adaption?

\subsubsection{Sample and setting}

The sample for this research consisted in two main groups: the technologists of the Humanities e-Learning Team and the university lecturers involved in the pilot projects of Blackboard 9.1 implementation. The first group consisted in about fifteen members from which only seven of them responded to the questionnaire. The second group was around forty different lecturers from the whole university. From this group only eighteen responded to the questionnaire. See table 1.

Table 1. Sample

\begin{tabular}{|lcccc|}
\hline Participants/Sex & Percentage & Feminine & Percentage & Masculine \\
\hline Technologists & $42.85 \%$ & 3 & $57.14 \%$ & 4 \\
\hline Lecturers & $33.3 \%$ & 6 & $66.7 \%$ & 12 \\
\hline
\end{tabular}

\subsection{Reliability}

One of the advantages of a questionnaire, in comparison with an interview, is that it tends to be more reliable; because it is anonymous, it encourages greater honesty, it is more economical than the interview in terms of time and money; and there is the possibility that it can be mailed' (Cohen et al., 2010, p. 158). On the other hand, the percentage of response is very low and this is one of the main problems that this research faced. Nevertheless, in this case, the rate of response was twenty-five out of fifty-five which is a good rate and the answers of the participants who completed the questionnaire were very extensive and well explained. This situation helped to gather useful information for the findings of the research, especially from the lecturers of the pilot projects. 


\subsubsection{Data gathering}

In order to facilitate the collection of data and to reach a higher number of people in a short period of time two questionnaires were developed to be applied among the participants of the research and both were emailed to the technologists and lecturers through mailing lists.

The idea of applying a questionnaire was addressed by the research questions and the nature of this research. As Oppenheim (2005, p. 10) mentions 'the formulation of any questionnaire to be used in a survey must be an integral part of the research design stage'. Thus, since the period of time to develop the investigation for a master degree is usually limited; a questionnaire was a good instrument to gather the data needed to answer to the research questions since the beginning of the investigation. The design of the questionnaire was developed around the information needed to answer the research questions. As Cohen et al. (2010, p. 318) suggest 'the process of operationalizing a questionnaire is to take a general purpose or set of purposes and turn these into concrete, researchable fields about which actual data can be gathered'. Thus, after the research questions were formulated the process to develop the questionnaire started.

Two different semi-structured questionnaires were designed using closed questions and also open-ended questions to allow the participants to give their own opinion about certain topics. As Cohen et al. (2010, p. 321) indicate 'there is a clear structure, sequence and focus, but the format is open-ended, enabling respondents to reply in their own terms'. This feature allows the participant to think his/her answer without limiting to an established set of answers. 'The semi-structured questionnaire sets the agenda but does not presuppose the nature of the response' (Cohen et al., 2010, p. 322). The closed questions used in the questionnaire allowed the analysis of the personal characteristics of the population such as sex, age, number of years working by the university, number of courses that they were teaching. These closed questions are useful to generate frequencies of response amenable to statistical analysis and treatment. (Cohen et al., 2010)

Scale of ordinal data was also included in one question of the technologists' questionnaire in order to measure the general feedback given by the lecturers during the pilot projects. For this question the scale used was from 'very satisfied' to 'very unsatisfied' in order to evaluate the level of satisfaction that the lecturers had during the pilots of the implementation of Blackboard 9.1. 


\subsubsection{Data Analysis}

In order to analyze the data collected through the questionnaires two different approaches were used. Firstly, since most of the questions were open-ended questions the analysis made was qualitative. Hence, the interpretation was a key to analyze the different responses. According to Stake (1995, p. 8) 'the most distinctive characteristic of qualitative inquiry is its emphasis in interpretation'. Secondly, quantitative analysis was used for the closed questions in order to establish percentages and graphics to represent some results.

\subsection{Validity}

The validation on any research is different according to its nature. In order to maintain the validity of this research from a qualitative point of view all the responses from the participants were kept intact. All the quotations taken from the participant's responses were not modified at any point. However, as in any qualitative data 'the subjectivity of respondents, their opinions, attitudes and perspectives together contribute to a degree of bias' (Cohet et al., 2010, p. 132).

Likewise, the quantitative analysis made to some of the questions using Excel programme contributed to represent important findings about the respondents. Nevertheless, as Cohen et al. (2010, p. 132) mention 'quantitative research possesses a measure of standard error which is inbuilt and which has to be acknowledged'.

\subsection{Limitations}

One of the main limitations that a case study research has is related with the generalization. As a case study, the research is focused in one specific case occurring in a specific place and time. Thus, the research might not be representative for any other cases. The social researcher is likely to confront skepticism about the findings skepticism which arises from doubts about how far it is reasonable to generalize from the findings of one case' (Denscombe, 2007, p. 42). Nevertheless, this research is useful to understand a general idea about technology implementation processes, as Nisbet and Watt cited by Cohen et al. (2010, p. 253) suggest 'a case study is a specific instance that is frequently designed to illustrate a more general principle'. 


\section{Findings}

The University of Manchester worked in the implementation of the virtual learning environment Blackboard 9.1 since September 2010. This research was focused on the implementation process from the point of view of the Humanities e-Learning team and the lecturers involved in the pilot projects. The two stages that were deeply studied during this research were the 'adoption stage' that it was the stage of the pilot projects. It started from September 2010 until May 2011. The second stage was the 'adaption stage'. This stage was the transition of the courses from Blackboard Vista to Blackboard 9.1 and it started from Mach 2011 until July 2011 when most of the lecturers started moving their courses into the new system.

The findings of the research were divided into two categories based on the type of questions. The qualitative and quantitative information gathered was also separate in different points presented in the table 2.

Table 2. Finding Categorization

\begin{tabular}{|ll|}
\hline \multicolumn{1}{|c|}{ Quantitative results } & \multicolumn{1}{c|}{ Qualitative results } \\
\hline - Information of the participants. & - Implementation of Blackboard 9.1 \\
\hline - Participation and role during the pilot projects. & $\begin{array}{l}\text { - Advantages about using Blackboard 9.1 instead } \\
\text { of Blackboard Vista }\end{array}$ \\
\hline - Technological tools used for teaching & - Disadvantages of Blackboard 9.1 \\
\hline - Levels of satisfaction using Blackboard 9.1. & - Satisfaction of using Blackboard 9.1. \\
\hline & $\begin{array}{l}\text { - General overview about Blackboard } 9.1 \\
\text { implementation process. }\end{array}$ \\
\hline
\end{tabular}

\subsection{Quantitative results}

The quantitative results of the research are summarized in the figures 1, 2, 3, 4 and are related to the information of the participants, their role and participation during the pilot projects, the technological tools used for teaching and the levels of satisfaction about using Blackboard 9.1. 


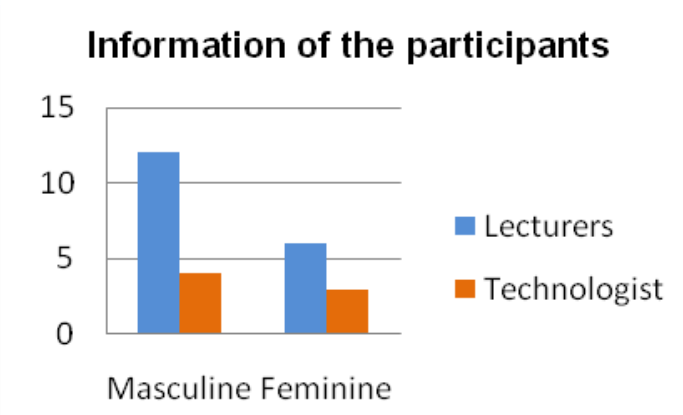

Figure 1

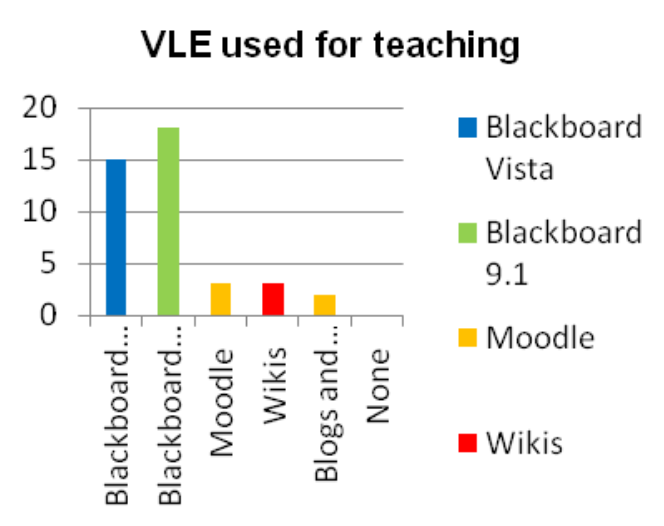

Figure 3
Role during the implementation process

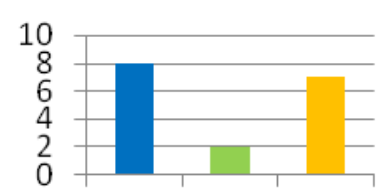

Course convenor

- Lecturer/Des igner

Academic Tutor

\section{Figure 2}

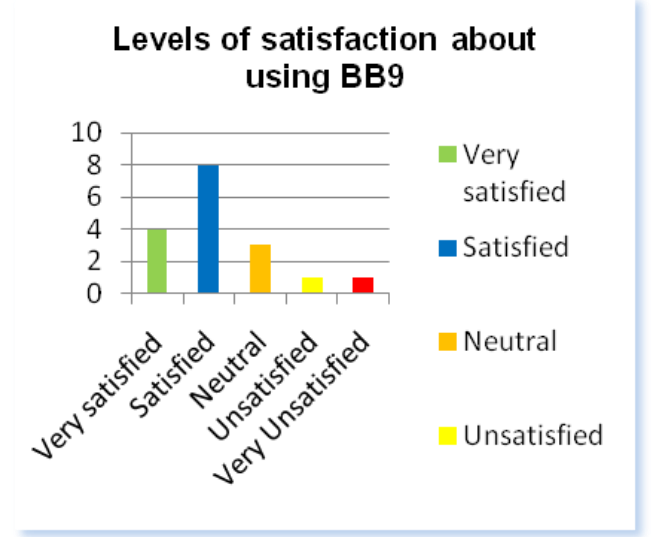

Figure 4

\subsection{Qualitative results}

The qualitative findings were made based on the responses that both lecturers and elearning technologies gave during the questionnaire application. The main points of the questionnaire were separated and analyzed in the following way.

\subsubsection{Implementation of Blackboard 9.1}

The general comments about the implementation process of Blackboard 9.1 revealed interesting information on how the lecturers and the technologists undertook this change of technology. 
From the technologists' opinion the implementation of Blackboard 9.1 was a decision made at management level. One of the technologist mentions that 'the decision to migrate was taken by high up management, who bought support from Blackboard.' In addition, another technologist only mentions 'decision taken at Senior Level without consultation'. From a social shaping of technology approach this demonstrates how some decisions are taken from higher levels and imposed to the whole institution. As Dutton et al (2004, p. 70) suggest, 'SST helps to focus attention on the manner in which an institution resists, assimilates, subverts or otherwise appropriates what is being proposed or imposed when a technical innovations threatens to disrupt the established ways of doing things.'

Furthermore, the main point about this is the way that the interests of some stakeholder groups are imposed on other groups based on the political positions or the power that they have within an organization as Cevero and Wilson (1994, p. 253) suggest in their theory about planning practice 'it is a social process of negotiating personal and organizational interests in contexts of structured power relations'. Therefore, this reflects how a decision made from a management department changed the functioning of a whole institution because according to the senate of the University of Manchester in June 2010 'the number of Blackboard Vista active users had increased from approximately 3,000 in June 2008 to 30,000 in June 2010'. It indicates that Blackboard Vista was well accepted and used by an increasing number of people within the university. However, regardless the acceptance of Blackboard Vista and based on political decisions, a new technology started its implementation in September 2010. Thus, the whole university community started a process of adaption and adoption of Blackboard 9.1, a technology that was 'threatening to disrupt the established ways of doing things' (Dutton et al, 2004).

From the lecturer's perspectives, there were two main general thoughts about the implementation of Blackboard 9.1 in the university. On the one hand a majority of the lecturers affirmed to be satisfied or very satisfied with the implementation of this new platform, as it was presented on the quantitative results. Likewise, most of the lecturers who affirmed to be satisfied with the new virtual learning environment mentioned that the layout is more appealing, the files are easier to move in comparison with Blackboard Vista and in general the system is more flexible to customize.

In contrast, several comments reflected the discomfort that a few lecturers had about implementing a new technology. Some of the comments were related to the long process that 
it took the adaption of Blackboard Vista. For example, one lecturer mentioned It has some advantages and some disadvantages, but not enough of them to justify all the fanfare and all the hassle of moving over. We wasted so much time with this seemingly endless process of re-engineering our e-learning provision because of changes in technology and environment'. This statement reinforces the idea of how the technologies are sometimes imposed into a community and the users are forced to confront a whole process of implementation, even though a new technology was recently implemented as it is the case of Blackboard Vista. From a social shaping of technology approach, it is important to take into account the opinion of the users most affected by the implementation of a new technology, for example teachers and students. 'A social-shaping perspective sensitizes research to the role of teachers since instructors are among the most critical decision makers on the adoption and use of technology in classes and for the way students organize their work with computers' (Layton, 1994).

Moreover, SST approach suggests that innovation is seen as a contradictory and uncertain process. Williams and Edge (1996, p. 873) indicate that

It is not just a rational-technical 'problem-solving' process; it also involves 'economic and political' processes in building alliances of interests (amongst, for example, supplier firms, technologists, potential users, funding bodies regulators) with the necessary resources and technical expertise, around certain concepts or visions of as yet unrealized technologies.

In the case of the University of Manchester and the implementation of Blackboard 9.1 the process was seen as contradictory from the perspective that one technology took almost two years to be adapted by the users and just when most of the staff, lecturers and students were accepting this technology another technology came to replace it.

Following a SST perspective, it is important to take into account the social groups that are affected with the implementation of a new technology. According to Howcroft, Mitev and Wilson (2004, p. 339) 'to understand the development of technology as a social process, it is crucial to take the artifacts as they are viewed by the relevant groups'. In this aspect the Humanities e-Learning team firstly made the pilot projects with a small number of lecturers in order to get some feedback before using Blackboard 9.1 with an extensive number of lecturers in the second phase of the pilots. As it was mentioned by one of the technologist, 
we had a small number of 'phase 1' piloters (2 from humanities) who wanted to try it out on their courses with their students, they received quite heavy support from us and the Blackboard trainer to put in place the things they used to do in Vista. During the first trial the system was put under testing, and from that bugs were fixed etc.

Moreover, Howcroft et al. (2004, p. 339) indicate the importance that social groups involved in the adoption of new technology have. About this point they suggest that 'the social groups play a crucial role in defining and solving the problems that arise during the development of technology'. In the case of Blackboard 9.1, the technologists of the elearning team took in consideration the participation, experiences and feedback of the pilot projects' lecturers to improve the implementation process of Blackboard 9.1 in the coming months. Based on the responses given by the technologists there were also different groups consulted about the implementation of Blackboard 9.1 in the university. See figure 5.

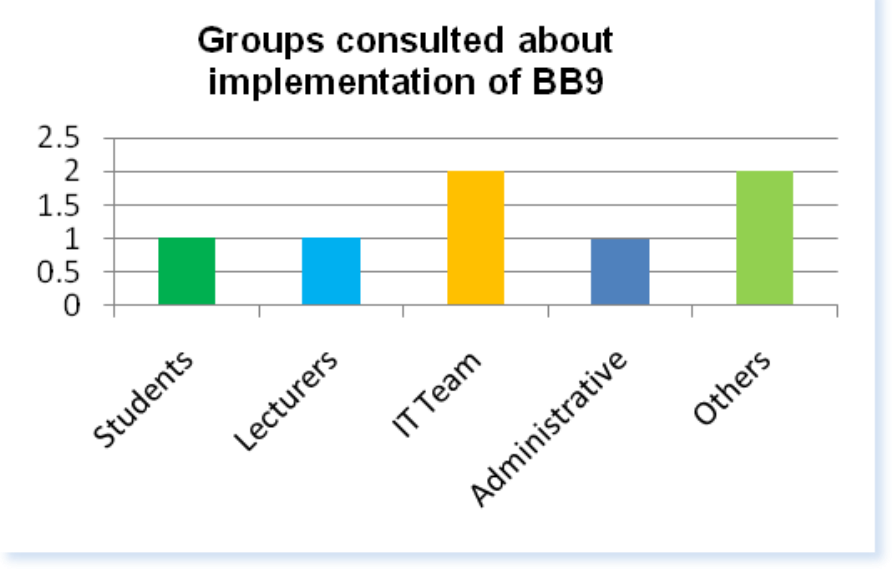

Figure 5

According to figure five, three out of seven technologists suggested that students, lecturers and administrative staff were consulted about the implementation of Blackboard 9.1. While four out of seven mentioned that IT Teams and other groups were also consulted about this change of technology. In the case of those who indicated that others groups were consulted, they specified that the IT department and e-Learning Managers probably discussed when Bb9.1 should be implemented. Also, one of them indicated that senior management was also consulted and finally one of the technologist mentioned that they were told that 'others' were consulted about this new technology implementation. Nevertheless, 
consultation is essential because every user can see the technology from its own perspective and as Mackay and Gillespie (1992, p. 709) indicate 'the user may bring to bear on a technology an intention which was not foreseen by the technology's designer'.

\subsubsection{Advantages about using Blackboard 9.1 instead of Blackboard Vista}

One of the points of finding how the implementation of a technology is undertaken in the higher education is related with the implications that the new technology will bring, in comparison with the current system. In the case of the University of Manchester, it was important to identify which advantages the users found about Blackboard 9.1 in comparison with Blackboard Vista, the current virtual learning environment when this study was developed.

The interface of Blackboard 9.1 was the most suggested advantage mentioned by both lecturers and technologists. About this idea, six out of eighteen lecturers suggested that the new system is more user friendly. Most of the comments made by the lecturers were about the system and its use. They felt this new system is friendlier than Blackboard Vista. About this idea one of the lecturer mentioned 'Bb9 is generally much more user friendly, the email tool was invaluable (especially being able to group students), easy hosting of videos and photos, looked professional, I liked the 'my places' link and the easy edit on/off, easy photo editing'. Moreover, the lecturers found that the interface of Blackboard 9.1 is better and clearer compared to the interface of Blackboard Vista.

A second advantage mentioned by the lecturers on the questionnaire was the design of Blackboard 9.1. Five out of eighteen lecturers mentioned that they liked different aspects of Blackboard related with the design. A lecturer mentioned 'more flexible: less rigid template for page design (more like a normal web-page, in fact)'. Furthermore, another lecturer commented 'more appealing layout overall'. Generally, the lecturers who mentioned characteristics about the design talked about the benefit to assembly their own course, the good visual integration of the elements on the screen and the flexibility for changing the page design.

Another positive feedback from lecturers was the email system from Blackboard 9.1. One of the lecturers mentioned 'direct email to students' better online quiz tool' while another said 'the email tool was invaluable, especially being able to group students'. Finally, two lecturers pointed out the design of the menu because it is easy to customize as it was 
mentioned by one of the participants, 'the customizable menu on the left-hand was an improvement and enabled us to design the navigation and structure of the course in a more useful way'. Additionally, a second participant said 'I liked the way that the menu for course units could be tailored to reflect the elements of the course unit'. Lastly, two of the lecturers commented that they did not find any advantage about moving to a new technology. The waste of time in training and the difficulties about changing all the courses from one technology to an updated version requires a lot of effort and time from all the lecturers.

All these points must be taking into account from a social shaping of technology approach because it is important to recognize the active role of the user of a given technology. As Mackay and Gillespie (1992, p. 702) mention the subjective, social appropriation of a technology is thus one key element of a technology - not just how it is used, but the meaning that use has for the user'.

\subsubsection{Disadvantages about using Blackboard 9.1 instead of Blackboard Vista}

Regardless the good feedback that Blackboard 9.1 had among the lecturers of the pilot projects, there are many points that the users identified as disadvantages, especially when they compare it with the Blackboard Vista version. The main ideas pointed by the lecturers were:

- Discussion boards: this tool in Blackboard 9.1 presented problems to be set up and it is not easy to integrate into the teaching process. One of the lecturers stated the discussion boards were not as easy to integrate into the course materials. It was noticeable that the use of the boards rapidly declined as the course went on.'

- Migration of the courses: one of the most concerning points about start using Blackboard 9.1 is the migration of materials from one platform to the other. With respect to this point Dyson (2011, p. 1) suggests 'academic colleagues will be responsible for setting up and building their courses in $\mathrm{Bb9}$, either from files they import from Blackboard vista 8, or from files they have saved on their computers'. Regarding this idea, one of the lecturers mentioned, 'the only disadvantage was the time consuming and difficult transition of materials from Vista to BB9.

- The lack of HTML: lecturers suggested that the lack of HTML make more difficult setting up courses and modifying content and design of the sites. 
- Assessment section: From the lecturers' perspective, Blackboard 9.1 presents a weakness in the assessment section. According to some of the lecturers, the new system is less flexible to upload assignments, deliver quiz and online tests and comparison of answers.

\subsubsection{Satisfaction of using Blackboard 9.1.}

A majority of lecturers seem to be satisfied about the implementation of this new platform in the university. Eight out of seventeen lecturers commented that they were satisfied with the new system. On the one hand, they mentioned that it had been a good support from the e-learning team to adopt this new platform. As one of the lecturer mentioned; 'lots of info, training and support has been given - including excellent getting started wizard'. Regarding this point, another lecturer considered that so far the new system had worked well and the e-learning team seemed to be doing a good job with the implementation process. On the other hand, those lecturers who affirmed to be satisfied with Blackboard 9.1 considered that the transfer of materials is manageable and not as complicated as some others think it would be.

Despite the support that Blackboard 9.1 had from many lecturers; there were still some lecturers who were unsatisfied about adopting this new technology. Firstly, most of the lecturers who were unsatisfied believed that the transfer of material from one technology to the other one was complicated. Building new courses from scratch seemed to be one of the main concerns of the pilot projects participants. Linked to this problem, one of them commented 'Transfer of courses from BB8 to BB9 not particularly well handled, in my view. In effect, courses have to be re-built from scratch -- there should have been a more open acknowledgement of this fact'.

Additionally, the participants commented that the decision about migrating to a new platform comes just when many lecturers were getting used to Blackboard Vista and using this virtual learning environment to support their teaching courses. About this point, one of the lecturers mentioned 'It is unfortunate that BB9 has come not long after most colleagues had finally established BB Vista presences for their courses. It feels like having to start all over again, with a big input of staff time required'.

Finally, the third point that gave the impression of bothering some lecturers is the fact that the decision of migrating to a new system was management-driven rather than teaching- 
driven and it was reflected in the way that implementation process was developed only two years after Blackboard Vista implementation started. Regarding this idea, one lecturer responded 'rationale for changeover has never been properly debated and explained. Implementation was manager-driven rather than lecturer-driven. Far too little prior consultation with academic teaching staff'. Additionally, other lecturer commented that 'It seems chaotic and a huge imposition on already overworked staff'. This situation revealed how in the University of Manchester, as in any large institution, the decisions were taken from political or economical reasons regardless the impact that the decisions would produce on the whole university community and its main actors; students and lecturers. According to Fincham, Fleck, Proter, Scarbrough, Tierney and Williams (1995)

Success in developing a technology is not just a matter of 'having the money' or of achieving good technical solutions. There may be difficulties, for example, in ensuring the flows of information between the various expert and specialist groups with their differing perspectives and knowledge bases, needed to create new technologies.

\subsubsection{General overview about Blackboard 9.1 implementation process}

The last part of the lecturer's survey was an open question regarding the lecturers if they have any comment about the implementation of Blackboard 9.1 in general. As part of the questionnaire design this last point seems to be repetitive to some of the lecturers. Nonetheless, ten out of eighteen lecturers wrote different comments about their general overview of this process addressing four main points. Firstly, they complained about the time consumed that the migration to the new technology had taken so far. Secondly, they considered that there was no reason to migrate to a new technology so soon. Thirdly, they commented that some aspects of the design were not appealing compared to Blackboard Vista. Finally, they highlighted that they had had a good support from the humanities elearning team throughout the whole implementation process, which was very useful to understand the technology and to adopt it.

\section{Conclusions}

The implementation of technologies in higher education requires a long process of planning where many different people are involved. An extended analysis of the implementation process of Blackboard 9.1 in the University of Manchester was undertaken, 
following a social shaping of technology approach. After the findings were analyzed these are the main conclusions of the research.

- The implementation process of Blackboard 9.1 in the University of Manchester was manager-driven instead of teaching-driven. Therefore, many lecturers were not satisfied with the decision of moving into a new platform. Regardless that lecturers and students are one of the most affected groups of the university community, the higher management departments of the institution decided to move into a more updated version of the current virtual learning environment by September 2011. This point is related to the levels of power that some stakeholders groups handle and their operating interests. As it was mentioned in the literature review, some stakeholder groups have the ability to influence the negotiations based on the power that they have and in this case was evident that the level of power of the senior management department allowed them to move forward with the decision of updating the VLE regardless the opinion of other stakeholder groups.

- There are many political and economical forces involved in the implementation process of Blackboard 9.1. It can be argued that some of the motivations behind the change were related to the Strategic Plan of the University of Manchester of becoming one of the top 25 universities of the world ranking by 2015. Nevertheless, there were also commercial reasons based on the contract signed with Blackboard Learn Company that were not analyzed during this piece of research.

- Neither students nor teachers or technologists were consulted before the implementation process of Blackboard 9.1 started. The decision was taken at senior level without consultation. From the lecturers' perspective, the rationale behind the change was never discussed or explained to the whole community and they received too little consultation about it.

- There was a large concern from the lecturers' community about the migration of courses from Blackboard Vista to Blackboard 9.1. Regardless the support that they had from the different e-learning teams the lecturers were worried about the time it takes to setting up the new courses in Blackboard 9.1. The lack of HTML to make small changes on the design and the difficulty to tailor the environment is one of main disadvantages that lecturers reported on the questionnaires. 
- The implementation process was done in a short period of time. This produced an overload of work to the lecturers who seemed to be worried about having everything ready for September 2011. They considered that it was not a right time to move into a new platform when most of the lecturers, students and staff just got used to the former virtual environment Blackboard Vista and they were using them to support their teaching and learning process. According to Lapointe and Rivards (2005, p. 462) 'resistance to a new technology is a critical variable that can be seen as a mean by which the users communicate their discomfort with a system that might be flawed'. Therefore, it is important from a technological point of view, to attend the negative feedback of the users as a priority in order to improve the use of the new system.

These conclusions are an important highlight to understand how the implementation of Blackboard 9.1 was undertaken by technologists and lecturers in the University of Manchester. Regarding the research questions of this dissertation, it can be said that from the teachers' perspective the implementation was undertaken firstly through the participation on the pilot projects of Blackboard 9.1 and secondly through the support given by the different elearning departments to migrate to the new system. Additionally, the teachers argued that the implementation was manager-driven and they were not consulted at any point about it. They felt well supported in terms of training and help given by the different e-learning teams and technologist of the university. However, the main concern that most of them still had by July 2011 was related to the migration of materials into Blackboard 9.1 and the time that it involved as it was mentioned before on the conclusions.

From the technologists' perspective, the implementation was undertaken through the three different stages; firstly with a small group of pilot projects; the second stage was incrementing the number of participants of the pilots and the third one was the mass migration of courses and materials into the new version of Blackboard before the new academic course started in September 2011. The technologists also shared the idea that the implementation was a decision taken from senior management and without consultation. They were in charge of all the training and support for academic and administrative levels throughout the 2010-2011 academic year. Some points such as the rationale behind the change and manager-driven decision of the implementation are interesting points to be developed in future research. 


\section{References}

Aidemar, Jan. (2007). IS Planning and Socio-Technical Theories Perspectives. Proceedings of European and Mediterranean Conference on Information Systems 2007, June 24-26. 441-449. Recuperado de: http://www.iseing.org/emcis/emcis2007/emcis07cd/EMCIS07PDFs/571.pdf

Barajas, Mario and Gannaway, Gloria. (2007). Implementing E-learning in the Traditional Higher Education Institutions. Higher Education in Europe, 32(2), 111-119.

Benson, Angela. (2002). Using Online Learning to Meet Workforce Demand: A case study of stakeholder influence. Quarterly Review of Distance Education, 3(4), 443-452.

Benson, Angela and Whitworth, Andrew. (2007). Technology at the planning table: Activity theory, negotiation and course management systems. Journal of Organisational Transformation \& Social Change, 4(1), 75-92.

Cervero, Ronald y Wilson, Arthur. (1994). The Politics of Responsibility: A Theory of Program Planning Practice for Adult Education. Adult Education Quarterly, 45(1), 249-268. Recuperado de: http://aeq.sagepub.com/content/45/1/249

Chin, Paul. (2003). Virtual Learning Environments. LTSN Learning and Teaching Support Network. Recuperado de: http://www.heacademy.ac.uk/assets/documents/subjects/ps/ps0081 virtual learning e nvironments sept 2003.pdf

Cradler, John. (1999). Implementing Technology in Education: Recent Findings from Research and Evaluation Studies. Technology Policy, Research \& Planning, Information and Resources. Recuperado de: http://neuage.org/portfolio/SilverDrive/more/implementingTechnology.htm

Cohen, Louis, Manion, Lawrence and Morrison, Keith. (2010). Research Methods in Education. London: Routledge.

Cooper, Randolph y Zmud, Robert. (1990). Information Technology Implementation Research: A Technological Diffusion. Management Science, 36(2), 123-139. Recuperado de: http://www.jstor.org/stable/2661451

Descombe, Martyn. (2007). The Good Research Guide for Small-Scale Social Research Projects. Berkshire, England: Open University Press, McGraw-Hill. Recuperado de: http://books.google.co.uk/books?hl=en\& $\mid r=\& i d=16 r R C 00 y o t k C \& o i=f n d \& p g=P P 1 \& d q=q u$ estionnaires+and++interviews+social+research\&ots=0BnnEIExY9\&sig=YHCygB XUGL 06soSgGiWffeblF4\#v=onepage\&q=questionnaires\%20and\%20\%20interviews\%20socia \%20research\&f=false

Downs, George and Mohr, Lawrence. (1976). Conceptual Issues in the Study of Innovation. Administrative Science Quarterly, 21(4), 700-714. Published by: Johnson Graduate 
School of Management, Cornell University. Recuperado de: http://www.jstor.org/stable/2391725

Dutton, William, Cheong, Pauline and Park, Namkee. (2004). The Social Shaping of a Virtual Learning Environment: The Case of a University-wide Course Management System. Electronic Journal of e-Learning @Academic Conferences Limited, 2(1), 69-80.

Dyson, Cathy. (2011). Faculty of Humanities Transition Approach in Phase 3 of the MLE project Support the transition to a new VLE Bb9. Recuperado de: http://www.humanities.manchester.ac.uk/tandl/elearning/documents/FoH TransitiontoB b9 Approach1-0.pdf

Finkelstein, Jonathan. (2006). Learning in Real Time: Synchronous Teaching and Leaning Online. California: Wiley Imprint.

Fincham, Robin, Fleck, James, Procter, Rob, Scarbrough, Harry, Tierney, Margaret and Williams, Robin. (1995) Expertise and Innovation: Information Strategies in the Financial Services Sector. Oxford: Clarendon Press.

Fullan, Michael. (1993). Change Forces: Probing the Depths of Educational Reform.London: Falmer Press; Levittown, PA, Falmer Press (Taylor and Francis Inc.).

Fry, Heather, Ketteridge, Steve and Marshall, Stephanie. (2003). A Handbook for Teaching \& Learning in Higher Education (2nd ed.). New York: Routledge. Recuperado de: http://biblioteca.ucv.cl/site/colecciones/manuales u/A\%20Handbook\%20for\%20Teachin g\%20and\%20Learning\%20in\%20Higher\%20Education\%20Enhancing\%20academic\%2 0and\%20Practice.pdf

Guri-Rosenblit, Sarah. (2005). Eight paradoxes in the implementation process of e-learning in higher education. Distances et savoirs, 4(2), 155-179.

Hall, Gene, Loucks, Susan, Rutherford, William and Newlove, Beula. (1975). Levels of Use of the Innovation: A Framework for Analyzing Innovation Adoption. Journal of Teacher Education, 16(1), 52-56.

Howcroft, Debra, Mitev, Nathalie N. and Wilson, Melanie. (2004). What we may learn from the social shaping of technology approach. In Leslie Willcocks and John Mingers (eds.), Social theory and philosophy for information systems (Wiley series in information systems, pp. 329-371). Chichester, Reino Unido: John Wiley \& Sons Ltd.

Jonassen, David, Davidson, Mark, Collins, Mauri, Cambell, John and Hagg, Brenda. (1995). Constructivism and Computer-Mediated Communication in Distance Education. The American Journal of Distance Education, 9(2), 7-25.

Keller, Christina. (2005). Virtual Learning Environments: Three Implementation Process. Learning, Media and Technology, 30(3), 299-311. 
Kwon, Te y Zmud, Robert. (1987). Unifying the Fragmented Models of Information Systems implementation. En Ricard Boland and Rudy Hirschheim (eds.), Critical issues in information systems research (pp. 227-251). New York, NY, USA: John Wiley \& Sons, Inc.

Lapointe, Liette and Rivard, Suzane. (2005). A Multilevel Model of Resistance to Information Technology Implementation. MIS Quarterly, 29(3), 461-491.

Layton, David. (1994). Technology and the classroom teacher. The International Encyclopedia of Education (Vol. 11, pp. 6283-6292). Estados Unidos, Husen and TN Postlethwaite Ed.

Lewin, Kurt. (1952). Group Decision and Social Change. Readings in Social Psychology (pp.459-473). New York: Newcomb and Hartley Ed.

Mackay, Hughie and Gillespie, Gareth. (1992). Extending the Social Shaping of Technology Approach: Ideology and Appropriation. SAGE Social Studies of Science Collection, 22, 685-716.

Mingers, John y Willocks, Leslie. (2004). Social Theory and Philosophy for Information Systems. Sussex, Chichester, Reino Unido: John Wiley \& Sons Ltd. West.

Mc Dougall, Anne and Jones, Anthony. (2006). Theory and history, questions and methodology: current and future issues in research into ICT in education. Technology, Pedagogy and Education, 15(3), 353-360.

Moersch, Christopher. (1995). Levels of Technology Implementation (LoTi): A Framework for Measuring Classroom Technology Use. Learning and Leading With Technology, International Society for Technology in Education, 23(3), 40-42.

Morgan, Sarah. (2010). Blackboard and the University of Manchester. Case study of Blackboard Vista. Reino Unido: Universidad de Manchester.

Oppenheim, Abraham. (2005). Questionnaire design, interviewing and Attitude Measurement. London: Printer Publications.

Roberts, Nathan, Grout, Vic and Worden, John. (2007). Adaptable and Collaborative Virtual Learning Environments Supporting Soft Skills. Computing (pp. 1-15). Recuperado de: http://epubs.glyndwr.ac.uk/cgi/viewcontent.cgi?article=1052\&context=cair

Stake, Robert. (1995). The Art of Case Study Research. Thousand Oaks, CS: Sage. Recuperado de: http://books.google.co.uk/books?hl=en\&lr=\&id=ApGdBx76b9kC\&oi=fnd\&pg=PR11\&dq= the+art+of+case+study+research\&ots=KtGNi1Npcl\&sig=iQle5B2LiNt0bTERotArz1VZk9

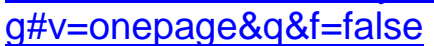

Sternberg, Elaine. (1997). The defects of stakeholder theory. Corporate Governance: an International Review, 5(1), 3-10. 
Tearle, Penni. (2003). ICT implementation: what makes the difference? British Journal of Educational Technology, 34(5), 567-583.

The University of Manchester, SENATE. (27 June, 2007). Acta. Recuperado de: http://documents.manchester.ac.uk/display.aspx?DoclD=8535

The University of Manchester, SENATE. (30 June, 2010). Acta. Recuperado de: http://documents.manchester.ac.uk/display.aspx?DoclD=8434

Weller, Martin. (2007). Virtual Learning Environments. Using, choosing and developing your VLE. London: Routledge.

Wilson, Melanie and Howcroft, Debra. (2000). The Politics of IS evaluation: a social shaping perspective. Proceedings of the Twenty -first International Conference on Information Systems, 94-103.

Whitworth, Andrew. (2005). The politics of virtual learning environments: environmental change, conflict, and e-learning. British Journal of Educational Technology, 36(4), 685691.

William, Robin y Edge, David. (1996). The social shaping of technology. Research Policy, ELSEVIER, 25, 865-899.

Yuen, Allan, Law, Nancy y Wong, K. (2003). ICT implementation and school leadership: Case studies of ICT integration in teaching and learning. Journal of Educational Administration, 41(2), 158-170. 